Article

\title{
New Design of the Reversible Jet Fan
}

\author{
Miroslav H. Benišek, Đorđe S. Čantrak * (D), Dejan B. Ilić (D) and Novica Z. Janković \\ Faculty of Mechanical Engineering, University of Belgrade, Kraljice Marije 16, 11120 Belgrade 35, Serbia; \\ mbenisek@mas.bg.ac.rs (M.H.B.); dilic@mas.bg.ac.rs (D.B.I.); njankovic@mas.bg.ac.rs (N.Z.J.) \\ * Correspondence: djcantrak@mas.bg.ac.rs
}

Received: 18 November 2020; Accepted: 15 December 2020; Published: 17 December 2020

\begin{abstract}
This paper presents two designs of the axial reversible jet fan, with the special focus on the impeller. The intention was to develop a reversible axial jet fan which operates in the same way in both rotating directions while generating thrust as high as possible. The jet fan model with the outer diameter $499.2 \pm 0.1 \mathrm{~mm}$ and ten adjustable blades is the same, while it is in-built in two different casings. The first construction is a cylindrical casing, while the second one is profiled as a nozzle. Thrust, volume flow rate, consumed power and ambient conditions were measured after the international standard ISO 13350. Results for both constructions are presented for three impeller blade angles: $28^{\circ}, 31^{\circ}$ and $35^{\circ}$, and rotation speed in the interval $n=400$ to $2600 \mathrm{rpm}$. The smallest differences in thrust, depending on the fan rotation direction, as well as the highest thrust are achieved for the first design with the cylindrical casing and blade angle at the outer diameter of $35^{\circ}$. Therefore, it was shown that fan casing significantly influences jet fan characteristics. In addition, the maximum thrust value and its independence of the flow direction is experimentally obtained for the angle of $39^{\circ}$ in the cylindrical casing.
\end{abstract}

Keywords: axial fan; reversible; jet; design; thrust; energy characteristics

\section{Introduction}

Reversible jet fans are present in road tunnels ventilation and garages, underground car parks, fire protection, good air quality systems, etc. They are designed to operate efficiently in both directions and produce adequate jets. Tunnel jet fans are, in fact, a substantial, i.e., core part of the tunnel ventilation, as well in smoke extraction systems. They should combine the highest technical requirements like efficiency and performance, as well as noise emission. Numerous CFD calculations have been performed in order to study the road tunnel ventilation and firefighting systems [1-8]. One of the choices for impulse ventilation of the tunnels is jet fan. "Impulse ventilation of tunnels involves the application of one or more jets of air into a tunnel, to drive the airflow in a desired direction. In essence, the kinetic energy of a high-velocity jet is transferred, with various degrees of efficiency, into the kinetic energy of slower-moving tunnel air" [4]. Therefore, the role of the jet fans is to provide

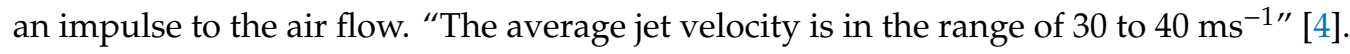

Experimental determination of tunnel ventilation axial ducted fan performance using a two-sensor hot wire X-probe with added pair of near-wall positioning pins is presented in [9]. Experimental results, obtained in the laboratory in the 1:19 scale tunnel, are used for ventilation performance of CFD test in a uni-directional traffic road tunnel $[3,9,10]$. Proposal for the improvement of CFD models of the tunnel fire development based on experimental data are also reported [7]. Improvement of the aerodynamic performance of a tunnel ventilation jet fan is performed by the application of multiobjective optimization technique [11].

Contemporary CFD tools include aerodynamic optimization of axial fan impeller with its blade geometry, guide vanes if they exist, casing and nozzle shapes, etc. Fan energy 
characteristics, i.e., the aerodynamic fan curves, prior to experiments, could be estimated numerically. Experimental validation could be done according to the international standard ISO 13350 [12].

Three high pressure reversible fan concepts, like a two-stage counter rotating fan, a single-stage high speed fan and a two-stage fan with a single motor and impeller on each end of the motor shaft are presented in paper [13].

Paper [14] presents the designed reversible jet fan, obtained experimental data and CFD results. Reversible aerodynamic design, in fact, limits the maximum fan pressure side [13]. Paper [15] presents a numerical optimization procedure for performance improvement of a jet fan. Authors in [16] point out that aerodynamically desirable axial fan rotor blades, which would have identical aerodynamic performances in both flow directions, are still insufficiently developed. They present a method to profile these blades.

This paper presents a design of the reversible jet fan, geometries of two versions of the casings and experimentally obtained data. The axial fan impeller is the same in both cases, while casings are different. Experimentally determined thrust, after ISO 13350 [12], power and volume flow rates for various fan rotation speeds in both rotating directions are presented in this paper. The intention was to design the impeller with good characteristics in both rotating directions, so the automatic fan speed control system could adopt the rotation direction depending on draft direction in the car tunnel. This should result in better maintenance of environmental conditions in car tunnels.

\section{Reversible Jet Axial Fan Designs}

The design is developed in cooperation of the Hydraulic Machinery and Energy Systems Department (HMESD) University of Belgrade Faculty of Mechanical Engineering (UB FME) and company Rudnap Group Minel Kotlogradnja from Belgrade, Serbia, where it was also manufactured. The demand from industry was to develop jet fan prototype with the following characteristics: volume flow rate- $Q_{p}=17 \mathrm{~m}^{3} \mathrm{~s}^{-1}$, impeller outer diameter- $D_{a, p}=0.71 \mathrm{~m}$, fan rotation speed $n_{p}=2950 \mathrm{rpm}$, fan motor power $-P_{p}=39 \mathrm{~kW}$ and axial force, i.e., thrust $-F_{z, p}=938 \mathrm{~N}$. Here, index " $\mathrm{p}$ " denotes "prototype". Axial thrust is calculated using the Equation (4). According to the reference [4]: "The average jet velocity is in the range of 30 to $40 \mathrm{~m} / \mathrm{s} . "$ This is, also, fulfilled for this prototype. These conventional jet fans are aligned parallel to the tunnel axis. The maximal achievable thrust $\left(F_{z, p, \max }\right)$ is calculated using Equation (6) in [4]. This relation could be simplified for the axial fan impeller in a free stream in the following way:

$$
F_{z, p, \max }=\rho A_{j} c_{z, j}\left(c_{z, j}-c_{z, f_{s}}\right),
$$

where $\rho$ is air density, $A_{j}$ is the jet fan outlet cross section, $c_{z, j}$ is the jet axial average velocity and $c_{z, f_{s}}$ is the free stream velocity, i.e., air velocity in the tunnel in the region without jet fan influence. Of course, the effective thrust is lower and calculated as follows:

$$
F_{z, p}=\rho A_{j} c_{z, j}\left(c_{z, j}-c_{z, f_{s}}\right) \eta_{p} \eta_{p, i n s t}
$$

where $\eta_{p}$ is the jet fan efficiency, and $\eta_{p, \text { ins }}$ is the jet fan installation efficiency. In some cases, it could be assumed that $\eta_{p}=1$ [4]. Installation efficiency depends on the jet fan position in the tunnel. It could be assumed that $\eta_{p, \text { ins }}=1$, if the jet fan is positioned in the middle of the tunnel, without the influence of other fans, other obstacles, as well as tunnel surfaces [4]. However, influence of the wall on the propulsion jet is studied in [16]. Therefore, the installation efficiency $\left(\eta_{p, \text { ins }}\right)$ could be estimated on the basis of Equation (9) in [4], which is derived using the experimental data presented in [17]. In the case of the presented constructions, the guide vanes and slanted silencers do not exist, so the regulation could be performed only by the fan speed rotation number. For the flow direction purpose, the flow straighteners in the "cross" shape are in-built in both silencers. The flow straighteners need to eliminate or, at least, minimize the turbulent swirling flow, which occurs behind the axial fan impellers [18], and maximize the axial velocity component which generates thrust. The sound power level according to the A-weighting was not experimentally determined. 
Jet fan head, i.e., pressure rise, could be determined in the following way:

$$
\Delta p_{t, p}=P_{p} \eta_{p} / Q_{p}=39 \cdot 10^{3} \cdot 0.55 / 17 \approx 1262 \mathrm{~Pa},
$$

where the jet fan efficiency could be estimated as $\eta_{p}=55 \%$. Besides Equation (2), thrust could be also determined as follows:

$$
F_{z, p}=\rho Q_{p} c_{z, p}=\rho Q_{p}{ }^{2} / A=938 \mathrm{~N},
$$

where $c_{z, p}$ is average axial velocity calculated as $c_{z, p}=Q_{p} / A$ and surface of the cross-section.

The jet fan model parameters are determined on the basis of the similarity law and equality of coefficients such as flow $(\varphi)$, head $(\psi)$, power $(\lambda)$ and efficiency $(\eta)$. Reversible jet fan model is developed using the following parameters: $D_{a}=0.5 \mathrm{~m}$ (punctually $499.2 \mathrm{~mm} \pm 0.1$ ) and fan power $P=3 \mathrm{~kW}$. By introducing power coefficient $(\lambda)$ as follows:

$$
\lambda_{p}=P_{p} /\left(D_{a, p}{ }^{2} u_{p}^{3}\right),
$$

where $u_{p}$ is circumferential velocity on diameter $D_{a, p}$. Equality of these coefficients for the prototype and model lead to the equation:

$$
n=n_{p}\left(P / P_{p}\left(D_{a} / D_{a, p}\right)^{5}\right)^{1 / 3}=2251 \mathrm{rpm} .
$$

Flow coefficient is derived, on the basis of kinematic similarity, as follows:

$$
\varphi=4 Q /\left[u_{a}\left(D_{a}^{2}-D_{i}^{2}\right) \pi\right],
$$

where $D_{i}$ is hub diameter.

Flow coefficients for the model and prototype are equal:

$$
\varphi=\varphi_{p}
$$

It is assumed that non-dimensional diameter $(v)$, defined as $v=D_{i} / D_{a}$, is equal for the model and prototype:

$$
v=v_{p}
$$

Volume flow rate of the jet fan model could be determined on the basis of Equations (7)-(9) as follows:

$$
Q=Q_{p} \cdot\left(\frac{D_{a}}{D_{a, p}}\right)^{3} \cdot \frac{n}{n_{p}}=17 \cdot\left(\frac{500}{710}\right)^{3} \cdot \frac{2251}{2950}=4.53 \frac{\mathrm{m}^{3}}{\mathrm{~s}} .
$$

Head coefficient $(\psi)$ is defined after the dynamic similarity as follows:

$$
\psi=2 Y / u_{a}^{2},
$$

where $Y$ is fan head defined in the following way:

$$
Y=\Delta p_{t} / \rho,
$$

where $\Delta p_{t}$ is difference of total pressures after and before the fan, i.e., total pressure rise in the jet fan.

Applying Equations (11) and (12), as well as introducing the equality of model and prototype head coefficients lead to the following expression:

$$
\Delta p_{t}=\Delta p_{t, p} \cdot\left(\frac{D_{a}}{D_{a, p}}\right)^{2} \cdot\left(\frac{n}{n_{p}}\right)^{2}=1262 \cdot\left(\frac{500}{710}\right)^{2} \cdot\left(\frac{2251}{2950}\right)^{2}=364.41 \mathrm{~Pa} .
$$


Using Equations (4) and (7), the following expression is derived:

$$
\frac{F_{z}}{D_{a}^{4} \cdot n^{2}}=\pi^{3} \cdot \varphi^{2} \cdot \rho \cdot \frac{\left(1-v^{2}\right)^{2}}{120^{2}} .
$$

Right hand side of the Equation (14), by assuming that air density is equal, depends only on flow coefficient and dimensionless radius, which are identical for the model and prototype, so the following equation for thrust could be derived:

$$
F_{z}=\left(\frac{D_{a}}{D_{a, p}}\right)^{4}\left(\frac{n}{n_{p}}\right)^{2} F_{z, p}=\left(\frac{500}{710}\right)^{4}\left(\frac{2251}{2950}\right)^{2} \cdot 938=134.32 \mathrm{~N} .
$$

In this way, all necessary data for jet fan model design are determined.

The greatest challenge was to develop axial fan impeller geometry to provide the same energy characteristics in both directions. It is even more important for the reversible axial fan functionality in traffic tunnels where pressure could vary in regions close to the inlet, i.e., exit. In this case, due to the fact that the complete fan construction cannot be rotated, or simpler geometries where blade angles cannot be adjusted, it is clear that axial fan impeller geometry must be symmetrical. This would result in the axial fan impeller with symmetrical blades. They should be designed in the way to use symmetrical airfoil and to be symmetrical to the axis normal to the chord, i.e., in this case, also camber line, which divides it in two halves. The fan is designed after the law of constant head in the radial direction, i.e., constant circulation in order to achieve higher energy efficient fans, i.e., equal energy distribution along the radius. The result is the twisted blade presented in Figure 1a. Threaded connection M20 is used for blade positioning in the axial fan hub. Six symmetrical profiles and their geometry are shown in Figure 1a. Geometry parameters for the first and sixth one are presented in Table 1, where r-radius measured from the axial fan rotation axis, R1-radius at the blade leading/trailing edge, R2 - radius of the profile pressure/suction side, $\beta$-profile angle measured from the fan rotation axis and ymax-maximum thickness. Profile maximum thickness is positioned in the center of the straight camber line, which has constant length along the blade $L=106 \mathrm{~mm}$.

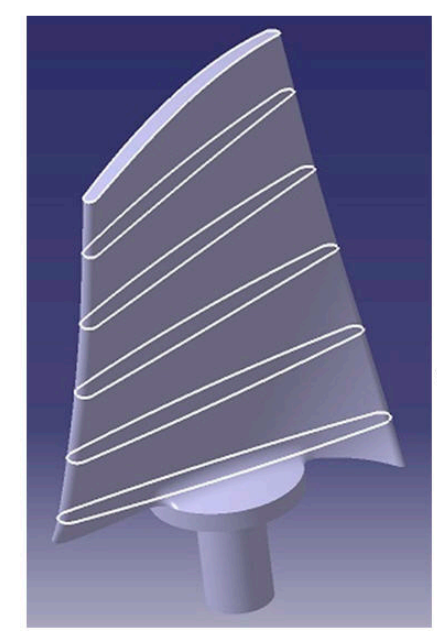

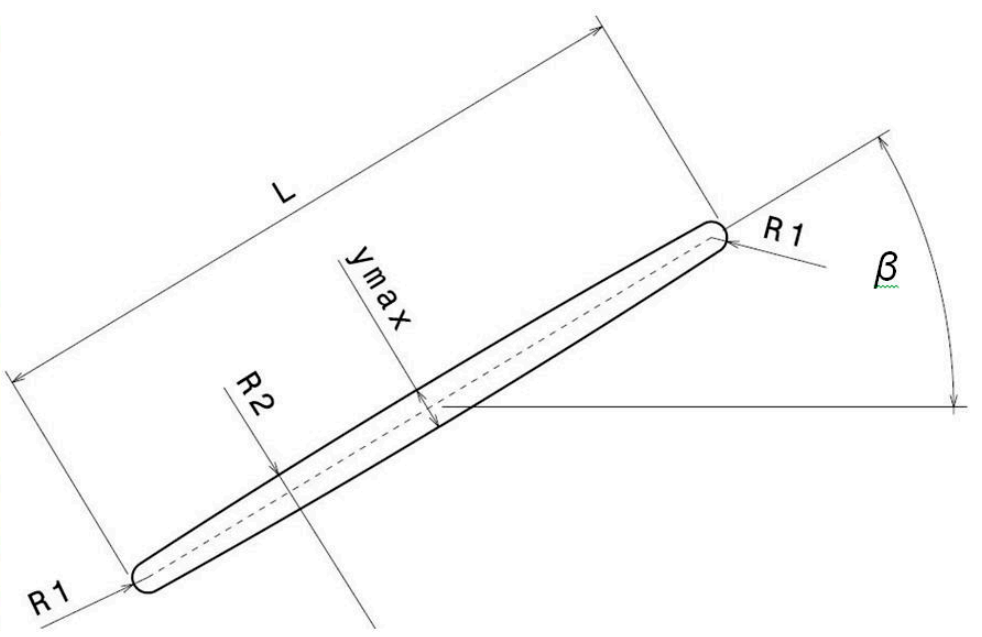

(a)

Figure 1. Cont. 


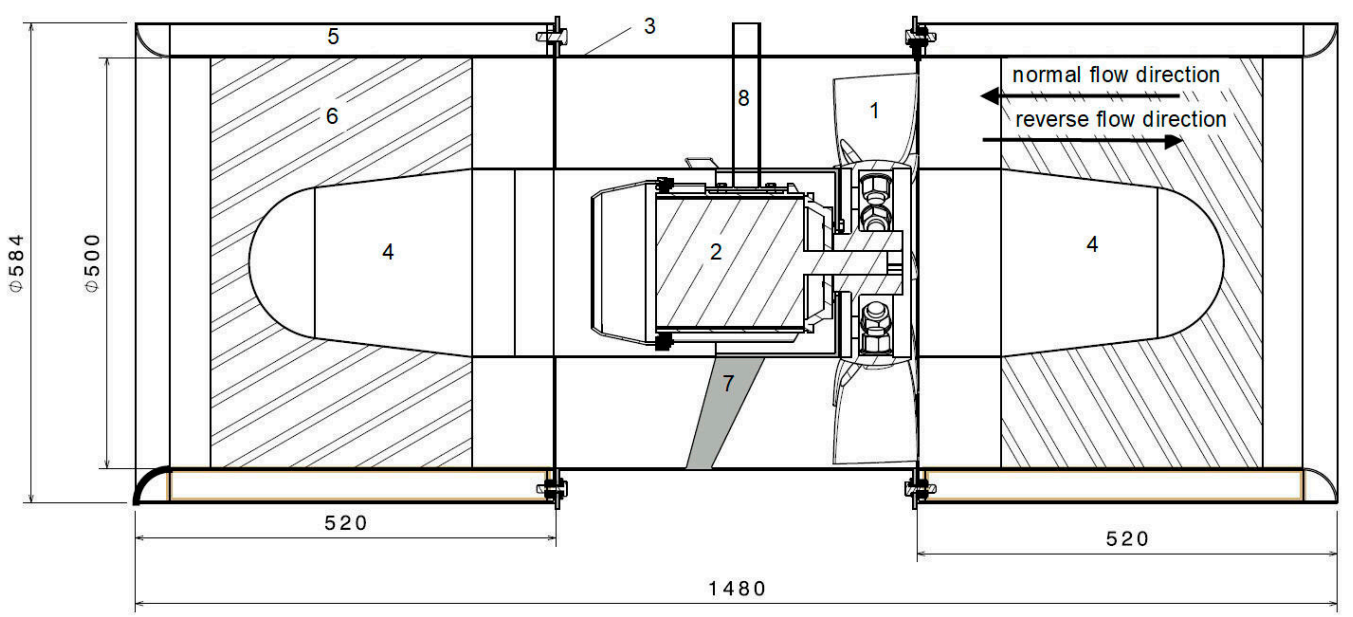

(b)

Figure 1. (a) Geometry of the impeller symmetrical blade and (b) Reversible jet axial fan with specified normal and reverse flow directions.

Table 1. Table of the geometry parameters of the symmetrical blade profiles (No. 1 and 6).

\begin{tabular}{ccccc}
\hline $\mathbf{r}[\mathbf{m m}]$ & $\mathbf{R} \mathbf{1}[\mathbf{m m}]$ & $\mathbf{R} 2[\mathbf{m m}]$ & $\boldsymbol{\beta}\left[{ }^{0}\right]$ & $\mathbf{y m a x}[\mathbf{m m}]$ \\
\hline 125 & 3.5 & 690 & 0 & 10.6 \\
250 & 2.1 & 1653 & 35 & 5.6 \\
\hline
\end{tabular}

Geometry of the whole construction of the reversible jet axial fan, with specified normal and reversible flow directions, is presented in Figure 1b, where: 1-impeller, 2-AC motor, 3-impeller casing, 4-profiled impeller hub cap, 5—silencer (sound suppressor), 6-flow straighteners, 7-AC motor support and 8-AC motor cable casing (pipe form). Flow straighteners are not specially profiled, due to the intention to obtain similar flow characteristics in both directions. They are only sheet metal parts which form the "cross" geometry.

Asynchronous electric motor with two poles is placed in the casing in the way not to disturb fluid flow. Axial fan casing with a hub and carrier is designed in the way to stabilize operation and connection with the electromotor.

The jet fan has profiled bell-mouth inlet, and casings have inner diameter of $500 \mathrm{~mm}$, while outer is $584 \mathrm{~mm}$ (Figure 1b). Casing consists of perforated plate, mineral wool and steel plate envelope, which minimize noise. Flow straighteners (Figure 1b, position 6) decrease generated turbulent swirling flow jet and direct the flow. Namely, the main role is to improve generated jet strength, i.e., maximize thrust and fan efficiency.

The jet fan model is designed for the following parameters determined above: fan rotation speed $-n=2251 \mathrm{rpm}$, volume flow rate $-Q=4.53 \mathrm{~m}^{3} \mathrm{~s}^{-1}$, impeller outer diameter- $D_{a}=0.5 \mathrm{~m}$ and axial force $-F_{z}=130 \mathrm{~N}$. It has ten adjustable blades and dimensionless ratio $v=D_{i} / D_{a}=0.5$. The manufactured jet fan model is presented in Figure 2. 


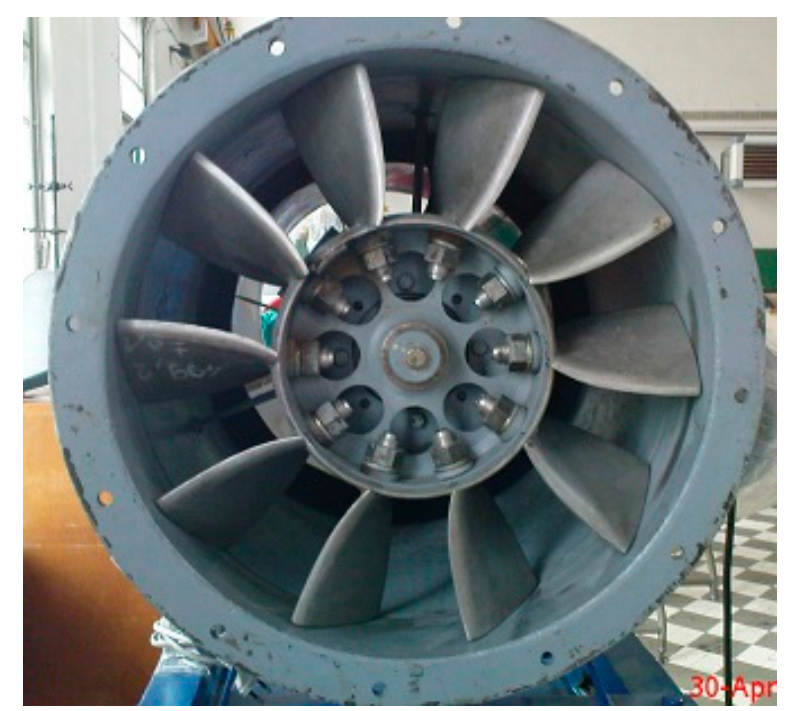

Figure 2. Developed axial fan impeller with its casing and AC electric motor.

The reversible jet fan 3D model was developed in academic software package CATIA V5R18 (64 bit) for the flow analysis. This model had certain level of "intelligence" based on the CATIA Knowledge tools, which provided blade angle easy variation and blade shape variation according to its angle position. In this way, clearances are minimized.

The second construction is with nozzles and flow straighteners as shown in Figure 3. It has nozzles with inner diameter $440 \mathrm{~mm}$ (Figure 3b).

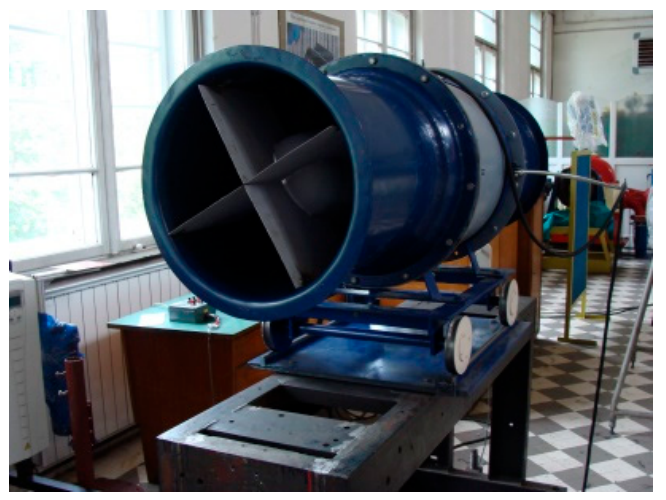

(a)

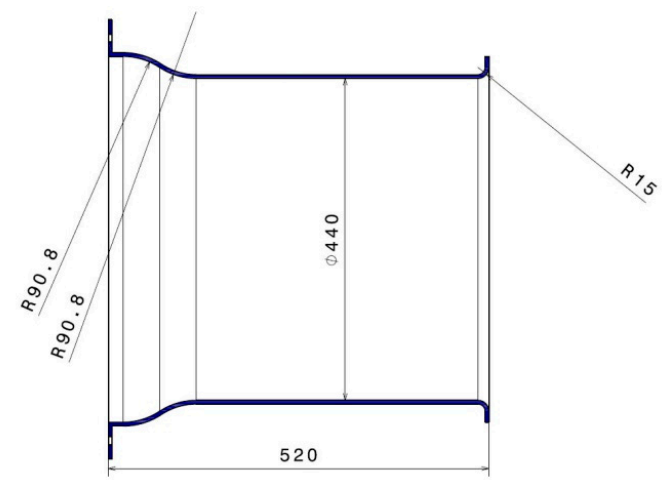

(b)

Figure 3. The second construction of the casing: (a) at the thrust measurement table and (b) nozzle geometry.

\section{Experimental Test Rig}

Experimental investigation of the designed jet fan was conducted on the designed and manufactured thrust measurement table in the Laboratory of the Hydraulic Machinery and Energy Systems Department at the Faculty of Mechanical Engineering University of Belgrade (Figure 4). 


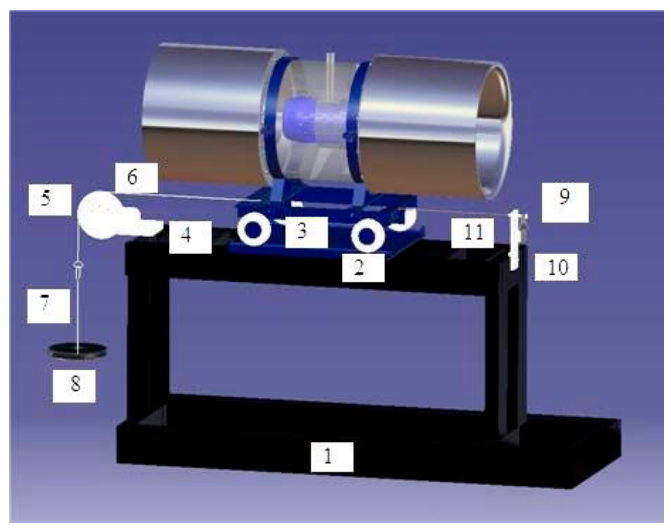

(a)

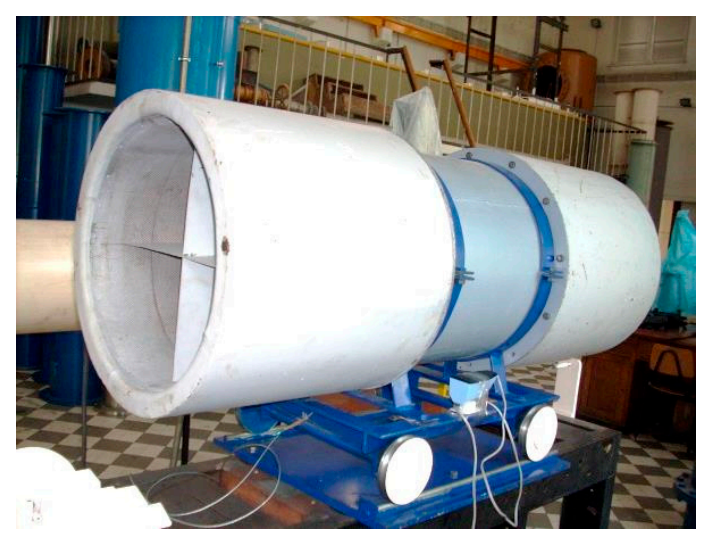

(b)

Figure 4. Thrust measurement table in the laboratory: (a) 3D model for calibration and (b) real model.

The test rig (Figure 4), i.e., the thrust measurement table, is composed of numerous elements. The fundament of the test rig construction is manufactured with massive steel U-shaped profiles (Figure 4a, position 1). It is heavy and provides operating stability important for obtaining precise measuring results. Rails are assembled with the steel plate to the fundament (Figure $4 \mathrm{a}$, position 2) so that axial fan with wheel chair could safely move along the rails and enable axial force, i.e., thrust measurements (Figure $4 a$, position 3). On the measurement table, a wheel fundament is attached, also made of steel. This wheel (pos. 5) is positioned on the wheel fundament (pos. 4) by the axle. Wheel rotation is possible by the use of radial rolling one-row bearing. Steel chrome polished cable with $3 \mathrm{~mm}$ in diameter (pos. 6) moves over it and connects weights carrier (pos. 7) with calibrated weights (pos. 8) and wheel chair. Weight carrier has two parts, of which the lower one is used for holding calibrated weights and the upper one is a hook for hanging on the steel rope. It is also calibrated and made of steel. Wheel chair is, on the other side, connected via measuring tape, with a force transducer (pos. 9). This is a construction for force transducer calibration. Calibration preceded each measurement. During measurements the steel cable is dismounted. However, the force transducer is always connected via measuring tape (pos. 11) with the wheelchair, and it is mounted on the steel carrier (pos. 10), which provides appropriate axial force measurements. The Vishay force transducer model 355, type C3, hermetically sealed, was used (Figure 5, pos. 1). Specified total error is $\pm 0.02 \%$ of rated output, which is here for $\mathrm{C} 3,50 \mathrm{~kg}$, i.e., $\pm 10 \mathrm{~g}$.

A force transducer was carefully calibrated at the thrust measurement table by first loading up to $45 \mathrm{~kg}$ and afterwards unloading due to hysteresis determination. A linear characteristic is obtained. A measuring tape transfers axial force from the axial fan to the force transducer. It provides stable work and precise measurements. A signal conditioner is used for the axial force transducer signal conditioning and acquisition. A frequency regulator is used to control the axial fan rotation speed. A digital frequency regulator DS2000, company MOOG, Serbia, was used. It has a three-phase regulator which works over the voltage interval from $65 \mathrm{~V}$ till $506 \mathrm{~V}$ and frequencies from 50 till $60 \mathrm{~Hz}$. Working temperature interval is 0 till $40^{\circ} \mathrm{C}$. A multifunctional measuring device Testo 450 with appropriate probes was used in these experiments for measuring air temperature and humidity, as well as for velocity measurements with attached vane anemometer probe. On the basis of the velocity measurements, in positions specified by ISO 5801 [19], the volume flow rate was determined. It is compared with the ones calculated on the basis of the measured axial velocity in the following way: $Q=D_{a}\left(F_{z} \pi / \rho\right)^{0.5} / 2$, where $\rho$ is air density. A mercury barometer measured atmospheric pressure before each test. Fan rotation speed was determined by a stroboscope DRELLOSCOP 3009. 


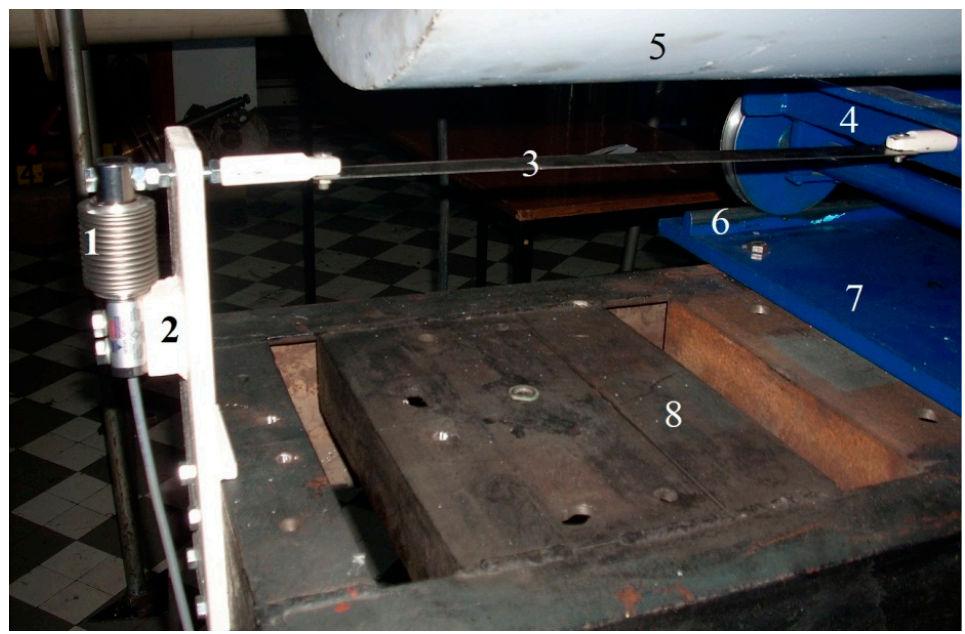

Figure 5. Connection of the force transducer with wheel chair: 1-force transducer, $\mathbf{2}$-force transmitter carrier, 3-measuring tape, 4-wheel chair, 5-axial fan, 6-rails, 7-steel plate for connection of rails with wheel chair loaded with reversible jet fan and 8 - fundament.

\section{Experimental Results and Discussion}

In the conducted experiments, the following physical values have been measured: axial force, i.e., thrust, velocity field at the fan inlet and outlet, fan rotation speed, electromotor power, air temperature, humidity and atmospheric pressure. Measurements were performed for various angle positions of both blade impeller sets, controlled at the outer diameter $D_{a}: \beta_{R a}=28^{\circ}, 31^{\circ}, 33^{\circ}, 35^{\circ}, 39^{\circ}$ and $45^{\circ}$ as well as for various fan rotation speeds $n=400,800,1200,1600,2080,2200,2500$ and $2565 \mathrm{rpm}$. Measurements have also been performed for both fan rotating, i.e., flow directions and are presented in Figure 6.

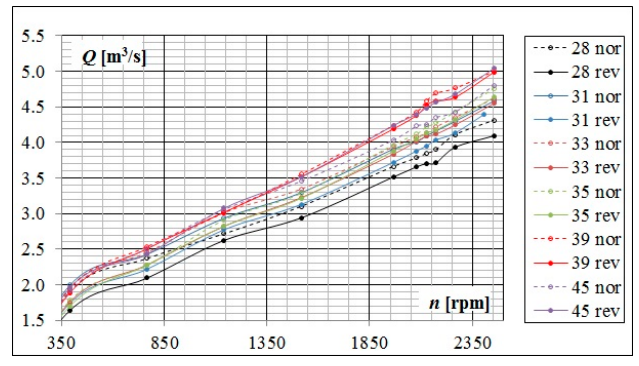

(a)

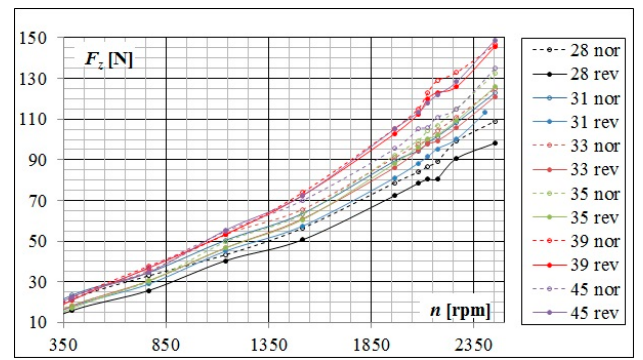

(c)

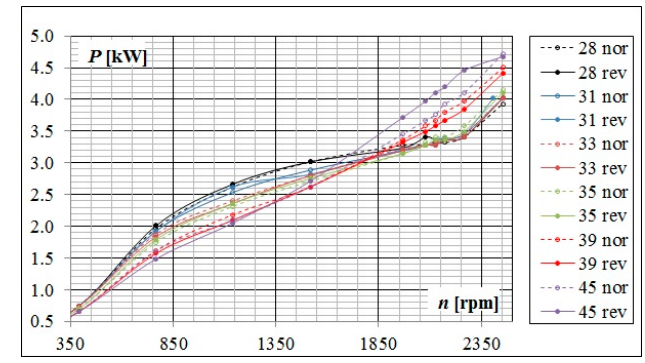

(b)

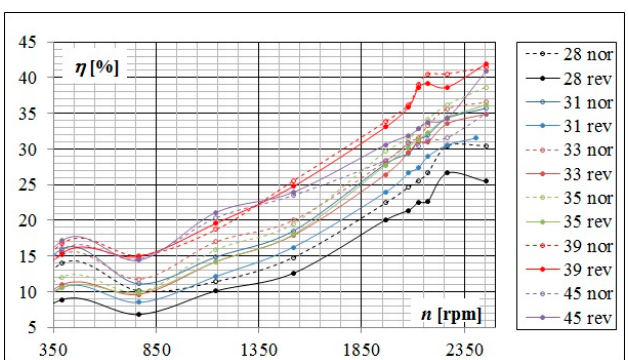

(d)

Figure 6. Reversible jet fan characteristics in the function of the fan rotation speed and angle $\beta_{R a}$ for both flow directions: (a) volume flow rate, (b) internal consumed power, (c) thrust and (d) efficiency. 
The fan efficiency is calculated, only after the contribution of the kinetic energy at the fan outlet, i.e., in the jet, as follows:

$$
\eta=Q \rho c^{2} / 2 P
$$

where $c$ is velocity at the fan outlet and $\rho$ air density. It is assumed that the inlet velocity is zero. It is calculated on the basis of the approximated internal power, presented in Figure $6 \mathrm{~b}$.

All fan characteristics, normally, increase with the fan rotation speed. Hierarchy of increasing the volume flow rate and thrust with increasing the blade angle, up to the angle $39^{\circ}$, is obvious. Fan characteristics depend on flow direction for all angles, but the smallest difference is obtained for angle $39^{\circ}$.

The best angle position $\left(\beta_{R a}\right)$ of the blade impeller blades is determined on the basis of a large amount of experimental data (Figure 6). Measuring results for the angle position at the outer diameter $\beta_{R a}=39^{\circ}$ are presented in the following charts (Figure 7).

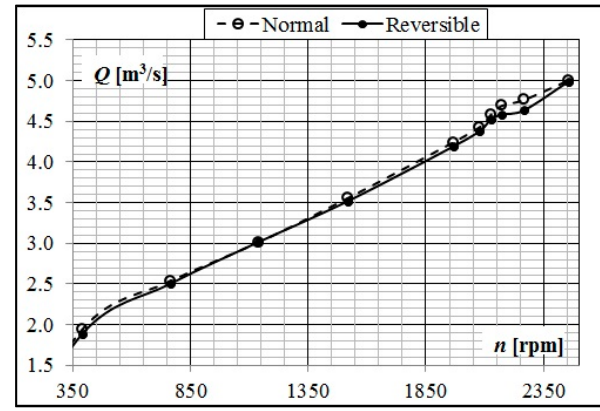

(a)

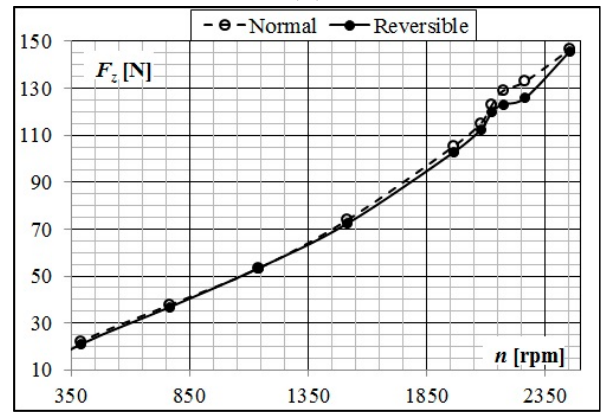

(c)

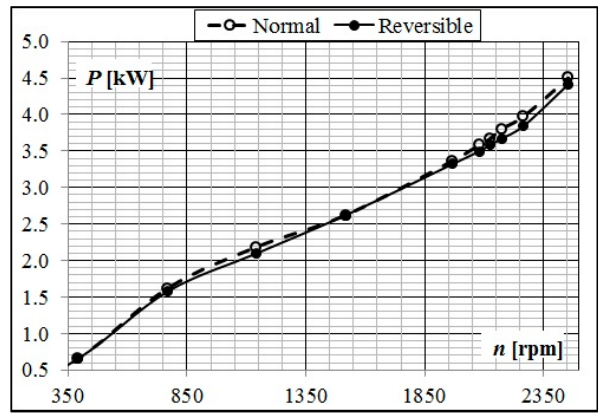

(b)

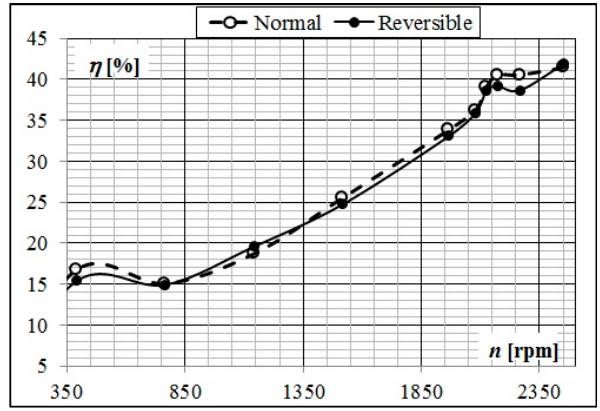

(d)

Figure 7. Reversible jet fan characteristics in the function of the fan rotation speed for both flow directions and angle $\beta_{R a}=39^{\circ}$ : (a) volume flow rate, (b) internal consumed power, (c) thrust and (d) efficiency.

Small differences of thrust are obtained for angle $\beta_{R a}=39^{\circ}$ depending on the flow direction in fan (Figure 7c). It is almost independent of the flow direction. This was the aim of this design. In this case, the maximum thrust is achieved in both directions (Figures $6 \mathrm{c}$ and $7 \mathrm{c}$ ). The fan was also tested for $\beta_{R a}=45^{\circ}$, but thrust started to decrease, i.e., is significantly lower for normal flow direction. In addition, the highest fan efficiency, calculated after fan contribution to the jet kinetic energy, is reached for angle $39^{\circ}$ (Figures $6 \mathrm{~d}$ and $7 \mathrm{~d}$ ), and it is almost the same for both flow directions $\eta_{I, \text { max }}=41.45 \%$ and $\eta_{I I, \text { max }}=41.94 \%$.

Obtained experimental results could be scaled-up to the prototype on the basis of the procedure presented in [14]. This procedure involves equality of the turbomachinery coefficients for flow, head and power. It is shown here that designed thrust of $134.32 \mathrm{~N}$ for rotation speed $2251 \mathrm{rpm}$ after Equation (15) is achieved for angle $39^{\circ}$. Obtained values are $F_{z}=133 \mathrm{~N}$ for $n=2266.8 \mathrm{rpm}$.

In addition, axial fan impeller was tested in two casing constructions. The first construction is a cylindrical casing, while the second one is profiled as a nozzle. Results for both models are presented and compared in Figure 8. This design was tested for $\beta_{R a}=28^{\circ}, 31^{\circ}$ and $35^{\circ}$. 


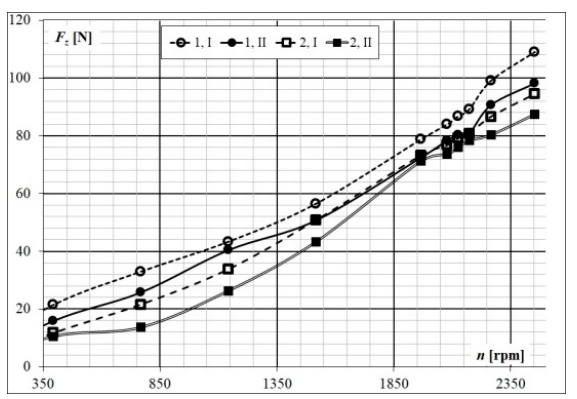

(a)

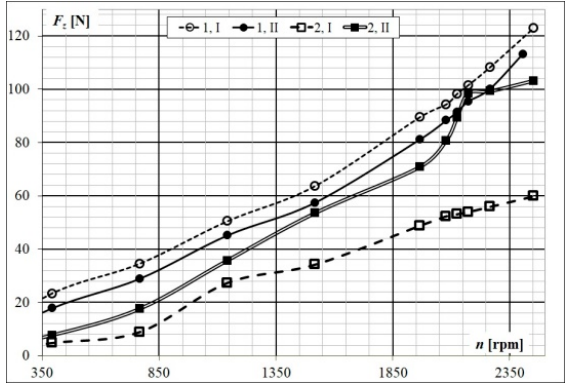

(b)

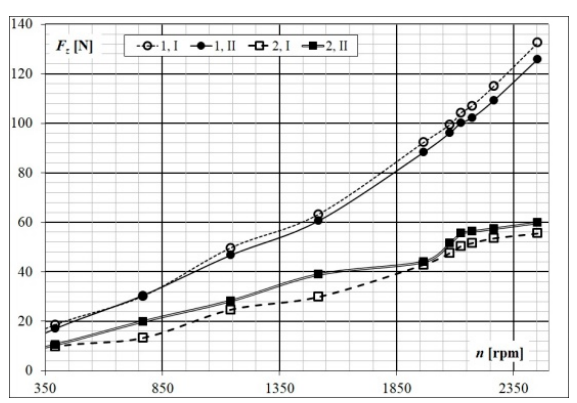

(c)

Figure 8. Comparison of the fan thrust in cylindrical (1) and nozzle (2) profiled casings for various angles $\beta_{R a}$ and rotational directions (I-normal and II-reversible flow directions) in the function of the fan rotation speed: (a) $28^{\circ}$, (b) $31^{\circ}$ and (c) $35^{\circ}$.

Angle $\beta_{R a}$ variation leads to good thrust in normal, while to worse ones in reversible flow direction (Figure 8). In all cases, the highest thrust values are reached for the highest fan rotation speed, what was expected. The smallest differences in thrust are achieved for $\beta_{R a}=35^{\circ}$ and presented in Figure 8c. This is obvious for the model 1 with cylindrical casing. The highest values of thrust are also achieved for this angle $\beta_{R a}=35^{\circ}$.

Influence of the flow direction in the reversible axial jet fan is more obvious for the second model with profiled nozzle. For this case significantly lower values of thrust are achieved for all angles $\beta_{R a}$. This is obvious for the highest presented angle $\beta_{R a}=35^{\circ}$ (Figure $8 \mathrm{c}$ ). It could be concluded that this nozzle casing was not properly designed for the tested fan. Construction of model 2 resulted in a lower flow rate and thrust.

Analysis of sources of error and of uncertainty evaluation for the thrust measurement is provided for the one measurement point $(n=2266.8 \mathrm{rpm})$ which is close to the designed fan rotation speed ( $n=2251 \mathrm{rpm}$ ). Calibration uncertainty of axial force (thrust) calibration, i.e., weights used for calibration, is $\pm 0.54 \mathrm{~g}$. Systematic uncertainty combines the uncertainty of transducer and calibration by the root-sum-square method and is $\pm 0.075 \%$. Random uncertainty of thrust measurements at $95 \%$ confidence level is $1.689 \%$, and total uncertainty of thrust measurement is $1.7 \%$. This is in accordance with the used standard ISO 13350.

\section{Conclusions}

This paper presents the design of the axial jet fan impeller with symmetrical and adjustable blades and experimental results of the testing on the test rig following ISO 13350. Two designs of fan casings are presented too. Axial fan was tested for various angles and rotation speeds in both cases. These fans work in pairs for the case of bigger tunnels, and the distance between two pairs of fans is, among other things, defined by the experimentally determined thrust. It could be concluded the following:

- Herein, the procedure is presented for determination of the jet fan model parameters on the basis of the parameters demanded for the prototype. This procedure is based on the geometry, kinematic 
and dynamic similarity law. Anyhow, this approach does not result in the same Reynolds number (Re), so $\Delta \operatorname{Re}$ is incorporated in the equation of recalculation/conversion, i.e., efficiency scale-up from a model to the prototype which is treated in IEC 60193. This is not discussed in the used standard here ISO 13350 [12].

- The test rig, i.e., thrust measurement table, for experimental investigations was designed and manufactured after the international standard ISO 13350. A force transducer was carefully installed and calibrated, and measure of uncertainty was determined.

- The main idea for this research was to design the axial fan with good thrust independent of the fan rotation direction.

- It was experimentally shown that differences for all fan characteristics depend on the flow direction in the axial fan, and this was noticed for almost all fan regimes and both casing designs. Hierarchical distribution of fan characteristics is present for almost all angles and rotation speeds up to the angle $39^{\circ}$. Thrust starts decreasing for the angle $45^{\circ}$ for normal flow direction (Figure $6 \mathrm{c}$ ). Therefore, this could be considered as a stalling effect which could occur for higher blade angles. Clearance is small in our design, but it increases with the blade impeller angle increment, and it has the highest value for $45^{\circ}$. Therefore, this loss of aerodynamic performance could be the consequence of the tip leakage vortex, i.e., flow from the blade tip with a strong vortex.

- Anyhow, the maximum thrust, and its almost independence of the flow direction is experimentally obtained for the angle at the fan outer diameter $\beta_{R a}=39^{\circ}$ (Figures $6 \mathrm{c}$ and $7 \mathrm{c}$ ). Flow rate and power are also independent of the flow direction in this case and reach the highest values for the maximum fan rotation speed (Figure 7a,b). The highest efficiency, calculated after Equation (16), is also achieved for this blade angle position (Figure 7d).

- In addition, it is shown that designed value for the thrust $F_{z}=134.32 \mathrm{~N}$ for rotation speed $n=2251 \mathrm{rpm}$ (Equation (15)) is achieved for angle $39^{\circ}$. Obtained thrust value is $133 \mathrm{~N}$ for $n=2266.8 \mathrm{rpm}$. Therefore, the complete design is proved here.

- It is shown that fan casing significantly influences jet fan characteristics. It has a convergent-divergent geometry (Figure $3 b$ ). This was an attempt to produce a fan with better characteristics. Some concepts are still under consideration.

- Experimentally determined thrust for the second design is presented and compared with the first one only for the angles $\beta_{R a}=28^{\circ}, 31^{\circ}$ and $35^{\circ}$ (Figure 8 ). The smallest differences in thrust depending on the fan rotation direction are achieved for the first design with cylindrical casing and angle at the outer diameter $\beta_{R a}=35^{\circ}$ (Figure $8 \mathrm{c}$ ). In this case, a significantly higher thrust is achieved than for the second design.

- It is shown that jet fan has a small reaction factor, and that in the best case, with the highest thrust, impeller specific energy is almost completely transformed into the kinetic energy achieving high velocities, high flow rates and thrust. This is why the efficiency rate is calculated and presented using Equation (16).

- Experimental results of the axial reversible jet fans testing are very rarely presented in the literature, so the adequate comparison of the obtained data was not possible. Obtained experimental results data basis is at disposal for CFD calculations for interested researchers.

Author Contributions: Conceptualization and methodology, all authors; validation, Đ.S.Č., N.Z.J. and D.B.I.; formal analysis, investigation and writing, all authors; All authors have read and agreed to the published version of the manuscript.

Funding: This research was funded by the Ministry of Education, Science and Technological Development, Republic of Serbia (MESTD RS), contract number 451-03-68/2020-14/200105 (subproject TR 35046) and by the Bilateral project "Joint Research on the Development Technology of Low-head Run-of-the-river Hydropower", between MESTD RS and Ministry of Water Resources in China and Renewable Energy and Rural Electrification Zhejiang International Science Center, contract number 401-00-00588/2018-09, which authors hereby gratefully acknowledge.

Acknowledgments: This article is partially based on a paper presented the 40th International HVAC congress, 2009, "Fan for Ecological Condition Sustain in Tunnels" held on 18-19 September 2009 in Belgrade, Serbia, 
so authors are thankful for technical support to M. Pajnić and M. Begović from Rudnap Group; Minela Kotlogradnja, Belgrade, Serbia.

Conflicts of Interest: The authors declare no conflict of interest.

\section{References}

1. Weisenpacher, P.; Valasek, L. Computer simulation of airflows generated by jet fans in real road tunnel by parallel version of FDS 6. Int. J. Vent. 2019. [CrossRef]

2. Brzezińska, D. Practical aspects of jet fan ventilation systems modelling in fire dynamics simulator code. Int. J. Vent. 2018, 17, 225-239. [CrossRef]

3. Šekularac, M.B.; Janković, N.Z.; Vukoslavčević, P.V. Ventilation performance and pollutant flow in a unidirectional-traffic road tunnel. Therm. Sci. 2017, 21 (Suppl. S3), S783-S794. [CrossRef]

4. Tarada, F.; Brandt, R. Impulse Ventilation for Tunnels-A State of the Art Review. In Proceedings of the 13th International Symposium on Aerodynamics and Ventilation of Vehicle Tunnels, New Brunswick, NJ, USA, 13-15 May 2009.

5. Rudelgass, H.; Barbetta, C. An Improved Jet Fan. Tunn. Tunn. Int. 2012, 7, 58-60.

6. Vidaković, B.M.; Banjac, M.J. Improvement of CFD models of tunnel fire development based on experimental data. Therm. Sci. 2017, 21 (Suppl. S3), S705-S716. [CrossRef]

7. Banjac, M.; Nikolić, B. Numerical Study of Smoke Flow Control in Tunnel Fires Using Ventilation Systems. FME Trans. 2008, 36, 145-150.

8. Viegas, C.J. The use of impulse ventilation to control pollution in underground car parks. Int. J. Vent. 2016, 8, 57-74. [CrossRef]

9. Šekularac, M.B. Experimental determination of tunnel ventilation axial ducted fan performance. Therm. Sci. 2016, 20, 209-221. [CrossRef]

10. Šekularac, M.B.; Janković, N.Z. Experimental and numerical analysis of flow field and ventilation performance in a traffic tunnel ventilated by axial fans. Theor. Appl. Mech. 2018, 45, 151-165. [CrossRef]

11. Kim, J.-H.; Kim, J.-H.; Yoon, J.-Y.; Choi, Y.-S.; Yang, S.-H. Application of multi-objective optimization technique to improve the aerodynamic performance of a tunnel ventilation jet fan. J. Mech. Eng. Sci. 2015, 229, 91-105. [CrossRef]

12. ISO. Standard ISO 13350:2015 Fans_Performance Testing of Jet Fans; ISO: Geneva, Switzerland, 2015.

13. Sheard, A.G.; Daneshkhah, K. The conceptual design of high pressure reversible axial tunnel ventilation fans. Adv. Acoust. Vib. 2012, 2012. [CrossRef]

14. Benišek, M.; Ilić, D.; Čantrak, Đ.; Božić, I.; Pajnić, M.; Begović, M.; Janković, N. Fan for Ecological Condition Sustain in Tunnels. In Proceedings of the 40th International HVAC Congress, Belgrade, Serbia, 2-4 December 2009; pp. 320-331. (In Serbian)

15. Kim, J.-H.; Kim, J.H.; Kim, J.-Y.; Yang, S.-H.; Choi, Y.-S. High-efficiency design of a tunnel ventilation jet fan thrugh numerical optimization techniques. J. Mech. Sci. Technol. 2012, 26, 1793-1800. [CrossRef]

16. Nishi, M.; Liu, S.; Yoshida, K.; Okamoto, M.; Nakayama, H. A new blade profile for bidirectional flow properly applicable to a two-stage jet fan. Int. J. Fluid Mach. Syst. 2009, 2, 449-455. [CrossRef]

17. Kempf, J. Einfluss der Wandeffekte auf die Treibstrahlwirkung eines Strahlgebläses. Schweiz. Bauztg. 1965, 83, 47-52.

18. Benišek, M.H.; Lečić, M.R.; Čantrak, Đ.S.; Ilić, D.B. The school of the turbulent swirling flow at the Faculty of Mechanical Engineering University of Belgrade. Therm. Sci. 2017, 21 (Suppl. S3), S899-S911. [CrossRef]

19. ISO. Standard ISO 5801:2017 Fans_-Performance Testing Using Standardized Airways; ISO: Geneva, Switzerland, 2017.

Publisher's Note: MDPI stays neutral with regard to jurisdictional claims in published maps and institutional affiliations.

(C) 2020 by the authors. Licensee MDPI, Basel, Switzerland. This article is an open access article distributed under the terms and conditions of the Creative Commons Attribution (CC BY) license (http://creativecommons.org/licenses/by/4.0/). 